\title{
Maximum Concentration Dose Normalized
}

National Cancer Institute

\section{Source}

National Cancer Institute. Maximum Concentration Dose Normalized. NCI Thesaurus.

Code C85698.

The maximum observed concentration divided by dose. 